УДК 615.322:582.916.6:547.814.5:543.422.3

\title{
ОПРЕДЕЛЕНИЕ ФЛАВОНОИДОВ В ЛИСТЬЯХ ФОРЗИЦИИ ПРОМЕЖУТОЧНОЙ (FORSYTHIA INTERMEDIA ZABEL.)
}

\author{
(ㄱ В.Н. Леонова*, О.И. Попова, И.А. Савенко
} Пятигорская государственная фрармацевтическая академия, пр. Калинина,
11, Пятигорск, 357532 (Россия), e-mail: sheryfka@mail.ru

В качестве объекта исследования использовали листья форзиции промежуточной. Целью работы явилось определение суммы флавоноидов листьев форзиции промежуточной. Проведены исследования по определению оптимального экстрагента, в качестве которого был выбран 70\% спирт этиловый. Методом дифференциальной спектрофотометрии в исследуемом объекте установлено количественное содержание суммы флавоноидов в пересчете на рутин $(2,05 \pm 0,052 \%)$.

Ключевые слова: форзиция промежуточная, листья, флавоноиды, дифференциальная спектрофотометрия.

\section{Введение}

Вот уже несколько десятков лет широко применяются фитопрепараты, что связано с их высокой эффективностью, комплексным воздействием на организм и малым, а зачастую и отсутствующим токсическим действием. Постоянно проводится поиск новых перспективных в лекарственном отношении растений.

Подспорьем в данной работе явилось изучение опыта народной медицины. Интерес к форзиции промежуточной (Forsythia intermedia Zabel.) семейства маслинные (Oleaceae) вызван ее широким применением в восточной медицине в качестве спазмолитического, противовоспалительного, противоопухолевого и антимикробного средства. По данным литературы, в официальной медицине Китая используются препараты на основе плодов форзиции [1]. Однако сведения о химической изученности и применении листьев форзиции промежуточной ограничены. Поэтому в качестве объекта исследования использовали листья. Немаловажным фактором выбора листьев в качестве объекта изучения явилось и то, что они имеют наибольшую массу, при их сборе не повреждается растение, что позволяет рационально использовать существующие насаждения, обеспечивая тем самым природоохранный подход при заготовке растительного сырья. Кроме того, форзиция как декоративное растение культивируется во многих странах мира, в том числе и в России (район Кавказских Минеральных Вод), используется в озеленении лесопарковой зоны. Различными методами хроматографического анализа, в том числе методом высокоэффективной жидкостной хроматографии (ВЭЖХ), с использованием стандартных образцов в спиртовом извлечении из листьев форзиции промежуточной установлено наличие флавоноидов (рутина, кверцетина, нарингинина).

В связи с вышеизложенным целью нашей работы явилось определение количественного содержания флавоноидов в листьях форзиции промежуточной.

Леонова Виктория Нодарьевна - преподаватель кафедры фармацевтической химии, кандидат фармацевтических наук, тел.: (8793) 39-10-87, e-mail: sheryfka@mail.ru

Попова Ольга Ивановна - профессор кафедры фармакогнозии, доктор фармацевтических наук Савенко Иван Андреевич - преподаватель и аспирант кафедры фармакологии и фармакотерапии, e-mail: vano93rus@bk.ru

\section{Экспериментальная часть}

Образцы сырья для исследования были заготовлены в 2009 г. в городских парках Пятигорска, Железноводска и Кисловодска. Образцы, собранные в фазе цветения, представляли собой цельные или частично измельченные листья, скрученные, яйце-

\footnotetext{
* Автор, с которым следует вести переписку.
} 
видные или эллиптические, слегка зубчатые, с 3-9 продольными дугообразными жилками, к основанию сужающиеся в тонкий сверху шероховатый, короткий черешок. Длина листовой пластинки 7-13 см, ширина около 5 см, длина черешка около 1,5 см. Цвет листьев с верхней и нижней стороны зеленый или буровато-зеленый. Запах слабый, вкус слабо-горьковатый. Измельченное сырье представляло собой кусочки листьев различной формы, проходящие сквозь сито с отверстиями диаметром 7 мм.

Для того чтобы получить из растительного сырья качественный препарат, необходимо иметь сведения об оптимальном экстрагенте. Поэтому на первоначальном этапе необходимо было провести данные исследования. В качестве экстрагента использован этиловый спирт различных концентраций: 30, 50, 70 и $90 \%$.

Количественное определение флавоноидов в спиртовых извлечениях проводили методом дифференциальной спектрофотометрии, основанной на реакции комплексообразования с хлоридом алюминия. Для устранения влияния не реагирующих с хлоридом алюминия сопутствующих окрашенных веществ на достоверность результатов количественного определения флавоноидов был выбран $\Delta$ Е-вариант дифференциальной спектрофотометрии с использованием раствора извлечения, не содержащего хлорид алюминия, в качестве раствора сравнения.

Оптимальным экстрагентом считался тот, который позволял определить наибольшее количество суммы флавоноидов в исследуемых извлечениях.

Далее проводили количественное определение суммы флавоноидов в листьях форзиции.

Методика количественного определения флавоноидов. Количественное определение суммы флавоноидов проводили по фармакопейной методике, приведенной в частной статье на траву зверобоя в ГФ ХІ, адаптированной для листьев форзиции промежуточной [2]. Для этого около 1,0 г (точная навеска) измельченного сырья помещали в колбу со шлифом вместимостью 150 мл, прибавляли 30 мл этилового спирта выбранной концентрации [2].

Колбу присоединяли к обратному холодильнику и нагревали на кипящей водяной бане в течение 30 мин, периодически встряхивая.

Горячее извлечение фильтровали через вату в мерную колбу вместимостью 100 мл. Вату с остатками сырья переносили в коническую колбу для экстрагирования и прибавляли 30 мл этилового спирта оптимальной концентрации.

Экстракцию проводили еще два раза в описанных выше условиях. Фильтровали полученные извлечения в ту же мерную колбу. После охлаждения объем извлечения доводили экстрагентом до метки и перемешивали.

Полученное таким образом извлечение фильтровали через бумажный фильтр, отбрасывая первые 5 мл фильтрата.

В мерную колбу вместимостью 25 мл помещали 2,5 мл извлечения, прибавляли 10 мл этилового спирта $95 \%$ и 2 мл $2 \%$-ного спиртового раствора хлорида алюминия. Через 10 мин прибавляли 0,1 мл разведенной уксусной кислоты и доводили объем раствора в колбе до метки этиловым спиртом 95\% (раствор А).

В мерную колбу вместимостью 25 мл помещали 2,5 мл извлечения, прибавляли 10 мл 95\%-ного этилового спирта. Через 10 мин прибавляли 0,1 мл разведенной уксусной кислоты и доводили до метки 95\%-ным этиловым спиртом (раствор Б) [3, 4].

Через 30 мин измеряли оптическую плотность раствора А относительно раствора Б на спектрофотометре СФ-2000 в кюветах с толщиной слоя 10 мм при аналитической длине волны $410 \pm 2$ нм.

Параллельно измеряли оптическую плотность раствора стандартного образца (РСО) рутина, приготовленного следующим образом: 0,05 г рутина (точная навеска) помещали в мерную колбу вместимостью 100 мл и доводили спиртом этиловым необходимой концентрации до метки. 1 мл полученного раствора помещали в мерную колбу вместимостью 25 мл и далее поступали так, как описано выше (приготовление растворов А и Б).

Расчет количества флавоноидов в персчете на рутин в абсолютно сухом сырье проводили по формуле:

$$
X_{\%_{c}}=\frac{A_{x} \cdot a_{c m} \cdot W_{x 1} \cdot W_{x 2} \cdot V_{a c m} \cdot 100 \cdot 100}{A_{c m} \cdot a_{x} \cdot V_{a x} \cdot W_{c m 1} \cdot W_{c m 2} \cdot(100-B)}=\frac{A_{x} \cdot a_{c m} \cdot 1 \cdot 100 \cdot 100}{A_{c m} \cdot a_{x} \cdot V_{a x} \cdot(100-B)},
$$


где $A_{x}$ - оптическая плотность испытуемого раствора; $A_{c m}$ - оптическая плотность раствора РСО рутина; $a_{x}$ - навеска листьев форзиции промежуточной, г; $a_{c m}$ - масса РСО рутина, $г ; V_{a x}-$ объем аликвоты испытуемого раствора, мл; $V_{a c m}$ - объем аликвоты раствора РСО рутина, мл; $W_{x 1}, W_{x 2}$ - объемы мерных колб, при приготовлении испытуемого раствора, мл; $W_{c m l}, W_{c m 2}$ - объемы мерных колб при приготовлении раствора РСО рутина, мл; $B$ - влажность растительного сырья, \%.

\section{Обсуждение результатов}

Данные по выбору оптимальной концентрации экстрагента представлены в таблице 1.

Из данных таблицы 1 следует, что максимальное извлечение суммы флавоноидов достигается при использовании 70\%-ного этилового спирта. Поэтому дальнейшие исследования проводили, используя спирт выбранной концентрации.

Результаты количественного определения флавоноидов в листьях форзиции промежуточной представлены в таблице 2.

Из данных таблицы 2 следует, что содержание

Таблица 1. Выбор оптимальной концентрации экстрагента

\begin{tabular}{c|c}
\hline $\begin{array}{c}\text { Концентрация этилового } \\
\text { спирта, \% }\end{array}$ & $\begin{array}{c}\text { Содержание } \\
\text { флавоноидов, \% }\end{array}$ \\
\hline 30 & 1,57 \\
50 & 1,62 \\
70 & 2,05 \\
90 & 1,65 \\
\hline
\end{tabular}
флавоноидов в пересчете на рутин с учетом влажности составило $2,05 \pm 0,052 \%$.

Таблица 2. Результаты количественного определения флавоноидов в листьях форзиции промежуточной

\begin{tabular}{c|c|c|c|c}
\hline № & $\mathrm{A}_{x}$, при $\lambda=408$ нм & $\mathrm{A}_{c m}$, при $\lambda=410$ нм & Содержание флавоноидов, $\%$ & Метрологические показатели \\
\hline 1 & 0,405 & & 2,03 & $\mathrm{X}=2,05$ \\
2 & 0,419 & 0,452 & 2,10 & $\mathrm{~S}=0,0418$ \\
3 & 0,411 & & 2,06 & $\mathrm{~S}_{x}=0,02$ \\
4 & 0,413 & 2,07 & $\Delta \mathrm{x}=0,052$ \\
5 & 0,397 & & 1,99 & $\varepsilon= \pm 2,54 \%$ \\
\hline
\end{tabular}

\section{Выводы}

Проведены исследования по выбору оптимального экстрагента для получения настойки форзиции промежуточной - 70\%-ный этиловый спирт. С помощью дифференциальной спектрофотометрии в исследуемом объекте установлено количественное содержание суммы флавоноидов в пересчете на рутин $(2,05 \pm 0,052 \%)$. Относительная ошибка определения составила $\pm 2,54 \%$.

\section{Список литературы}

1. Шретер А.И. Природное сырье китайской медицины : в 2 т. М., 2004. Т. 1.840 с.

2. Государственная фармакопея СССР: Общие методы анализа : в 2 т. 11-е изд., доп. М., 1987-1989. Вып. 1, 2.

3. Барковский В.Ф., Ганапольский В.И. Дифференциальный спектрофотометрический анализ : справочник. М., 1969. $168 \mathrm{c}$.

4. Краснов Е.А., Березовская Т.П., Алексеюк Н.В. и др. Выделение и анализ природных биологически активных веществ. Томск, 1987. 193 с. 
Leonova V.N.", Popova O.I., Savenko I.A. DEFINITION OF FLAVONOIDES IN LEAVES OF FORSYTHIA INTERMEDIATE (FORSYTHIA INTERMEDIA ZABEL.)

Pyatigorsk State Pharmaceutical Academy, pr. Kalinina 11, Pyatigorsk, 357532 (Russia), e-mail: sheryfka@mail.ru

As object of research used of forsythia intermediate leaves. The purpose of work was definition of the sum flavonoides in forsythia intermediate leaves. Are carried out researches by definition optimum extragent as which $70 \%$ spirit ethyl have been chosen. The method of differential spectrofotometry in investigated object installs the quantitative maintenance of the sum flavonoides in recalculation on routines $(2,05 \pm 0,052 \%)$.

Keywords: forsythia intermediate, leaves, flavonoides, differential spectrofotometry.

\section{References}

1. Shreter A.I. Prirodnoe syr'e kitaiskoi meditsiny [The natural raw materials of Chinese medicine]. Moscow, 2004, vol. 1.840 p. (in Russ.).

2. Gosudarstvennaia farmakopeia SSSR: Obshchie metody analiza : $v 2$ t. 11-e izd. [State Pharmacopoeia of the USSR: General methods of analysis: in 2 vol 11 ed.]. Moscow, 1987-1989, no. 1, 2. (in Russ.).

3. Barkovskii V.F., Ganapol'skii V.I. Differentsial'nyi spektrofotometricheskii analiz: spravochnik. [Differential spectrophotometric analysis: a guide]. Moscow, 1969, 168 p. (in Russ.).

4. Krasnov E.A., Berezovskaia T.P., Alekseiuk N.V. et al. Vydelenie i analiz prirodnykh biologicheski aktivnykh veshchestv. [Isolation and analysis of biologically active substances]. Tomsk, 1987, 193 p. (in Russ.).

Received July 4, 2011

\footnotetext{
* Corresponding author.
} 